Tropical Journal of Pharmaceutical Research July 2019; 18 (7): 1519-1526

ISSN: $1596-5996$ (print); 1596-9827 (electronic)

(C) Pharmacotherapy Group, Faculty of Pharmacy, University of Benin, Benin City, 300001 Nigeria.

Available online at http://www.tjpr.org

Original Research Article

http://dx.doi.org/10.4314/tjpr.v18i7.23

\title{
Mechanism of Klebsiella pneumoniae resistance to carbapenem antibiotics
}

\author{
Danxia Chen ${ }^{1}$, Yan $\mathrm{Zhu}^{1}$, Liangshan $\mathrm{Hu}^{1}$, Xiaoyun $\mathrm{Wu}^{1}$, Mingyou $\mathrm{Li}^{1}$, HanHui \\ $\operatorname{Lin}^{2 *}$ \\ ${ }^{1}$ Department of Laboratory Medicine, Guangdong Second Provincial General Hospital, No.466 Xingang Middle Road, Haizhu \\ District, Guangzhou 510317, Guangdong Province, ${ }^{2}$ Center of Faculty Development and Educational Technology, Information \\ Science School and School of Statistics and Mathematics, Guangdong University of Finance and Economics, Guangzhou \\ 510320, China
}

*For correspondence: Email: czgdcc@qq.com

Sent for review: 23 April 2019

Revised accepted: 29 June 2019

\begin{abstract}
Purpose: To investigate the mechanism of action of Klebsiella pneumoniae (Kpn) resistance to carbapenem.

Methods: The susceptibility of six Klebsiella pneumoniae strains to antibiotics was determined using K$B$ assay. Six isolated strains which were resistant to carbapenem were identified and collected using modified Hodge test. The phenotypes of metal enzyme were evaluated by ethylene diamine tetraacetic acid (EDTA) disk diffusion method. The genes for beta-lactamases, including KPC gene, were examined.

Results: The six carbapenem-resistant strains of Klebsiella pneumoniae were resistant to imipenem, meropenem and aztreonam, but were sensitive to amikacin, fosfomycin, minocycline, and polymyxin. The six pathogens did not produce metal enzyme, but they produced carbapenemases. Moreover, the six strains partially carried blaTEM or blaSHV gene, but all had blaKPC-2 gene.

Conclusion: These results suggest that the pathogens that contain blaKPC-2 gene may be involved in the mechanism of Klebsiella pneumoniae (Kpn) resistance to carbapenem.
\end{abstract}

Keywords: Klebsiella pneumoniae, $\beta$-Lactamase, Carbapenemase, Resistance mechanism

This is an Open Access article that uses a fund-ing model which does not charge readers or their institutions for access and distributed under the terms of the Creative Commons Attribution License (http://creativecommons.org/licenses/by/4.0) and the Budapest Open Access Initiative (http://www.budapestopenaccessinitiative.org/read), which permit unrestricted use, distribution, and reproduction in any medium, provided the original work is properly credited.

Tropical Journal of Pharmaceutical Research is indexed by Science Citation Index (SciSearch), Scopus, International Pharmaceutical Abstract, Chemical Abstracts, Embase, Index Copernicus, EBSCO, African Index Medicus, JournalSeek, Journal Citation Reports/Science Edition, Directory of Open Access Journals (DOAJ), African Journal Online, Bioline International, Open-J-Gate and Pharmacy Abstracts

\section{INTRODUCTION}

The resistance of some Enterobacteriaceae strains to extended-spectrum cephalosporins has become a thorny issue in clinics all over the world [1]. Klebsiella pneumoniae and Escherichia coli produce extended spectrum $\beta$-lactamases (ESBLs) which have led to the use of more carbapenems in the treatment of serious infections in hospitalized patients [2]. Later on, carbapenemases were discovered, including class B metallo- $\beta$-lactamases VIM, IMP, SPM and GIM [3]. These enzymes contain zinc in their active sites. They are mainly found in Acinetobacter and Pseudomonas species, but are rarely detected in Escherichia coli and Klebsiella pneumoniae. In the late 1990s, Klebsiella strains that were less susceptible to 
carbapenem antibiotics were reported in New York City, North Carolina and Maryland [4]. Many hospitals in New York City had reported strains that were less susceptible to carbapenem antibiotics. Initially, some researchers tried to assay metal beta-lactamases in these strains, but the MICs of carbapenem on these strains were not inhibited by EDTA as expected, which confirmed that the bacteria produced KPC carbapenem-hydrolyzing enzymes [5].

The clinical isolation rate of imipenem-resistant Enterobacteriaceae (imipenem-resistant Enterobacter, IRE) has continued to rise [6]. The emergence of carbapenem-resistant Enterobacteriaceae was of great importance to clinical antiinfective therapy [7]. One of the main mechanisms of carbapenem antibiotic resistance was bacterial production of Klebsiella pneumoniae carbapenemases (KPCs) [8]. The first KPC was reported in the United States in 2001 [9]. Enterobacteriaceae bacteria that subsequently produce KPC enzymes are continuously being identified in the United States [10]. Twenty-four states in the United States have reported production of KPC enzyme strains that have caused epidemics in the states of New York and New Jersey in the eastern United States. Moreover, clinical cases of infection with KPC-producing strains have been reported in France, Colombia, Greece, United Kingdom, Argentina, Brazil, Norway, Sweden and China [11]. Currently, majority of Klebsiella pneumoniae producing KPC-2 or KPC-3 are mainly cloned [12]. The KPC-producing strains are not easily detected in the laboratory, because many strains may be with similar phenotypic characteristics of KPC-producing strains, and sensitive to imipenem or meropenem [13]. Ertapenem is a better indicator of KPC enzyme than other carbapenem antibiotics [14]. The KPC genes are often located on larger plasmids, which in turn often carry other drug-resistant genes, resulting in multiple drug resistance and increasing the difficulty of treatment [15].

The resistance to extended-spectrum cephalosporins in Enterobacteriaceae strains has become a serious medical issue in recent years. Therefore, the current study was carried out to investigate the mechanism involved in Klebsiella pneumoniae (Kpn) resistance to carbapenem.

\section{EXPERIMENTAL}

\section{Klebsiella pneumoniae strains}

The Klebsiella pneumoniae strains were collected in Guangdong Second Provincial General Hospital, Southern Medical University, from January 2017 to September 2017. The Klebsiella pneumoniae strains were derived from sputum or airway secretions of six different patients with lung infection. All the six specimens of Klebsiella pneumoniae strain were resistant to carbapenem (imipenem or meropenem). The ages of the six patients ranged from 70 to 90 years, and they comprised 4 males and 2 females. They were admitted with infectious diseases, and there were large areas of shadow in their lungs. The patients had dyspnea, in addition to different degrees of increases in white blood cell count and C-reactive protein (CRP). There were invasive procedures and history of high-dose broad-spectrum antibiotic use before admission. Specimens were identified by the API Method Bacteria Identification System from Merial, France. The control strain used was Escherichia coli ATCC25922. This research was approved by the Ethical Committee of Center of Faculty Development and Educational Technology, Information Science School and School of Statistics and Mathematics, Guangdong University of Finance and Economics, Guangzhou, China (approval no. 201815165), and followed the guidelines of the Declaration of Helsinki promulgated in 1964 as amended in 1996 [16].

\section{Drug-sensitive test strips and main reagents}

Drug-sensitive paper was purchased from Beijing Tiantan Biological Products Co., Ltd. The main antibacterial agents were cefotaxime CTX, ceftazidime, cefuroxime, amoxicillin/clavulanic acid (AMC), ampicillin (AM), ampicillin/sulbactam (GEN), cotrimoxazole (SXT), cefoperazone/ sulbactam (SCF), piperacillin/azobactam (TZP), ATM, cefepime (FEP), levofloxacin (LEV), meropenem (MEM), imipenem (IPM), polymyxin $B$ (PO), fosfomycin (P), amikacin (AN) and minocycline. Extraction Kit for DNA Plasmid and DNA Gel Recovery Kit were purchased from Wiegers Biotech (Beijing) Co., Ltd. Taq enzyme was purchased from Shanghai Dingguo Biotechnology Co., Ltd, while T4 DNA ligase and IPTG were purchased from Promega. Restriction endonuclease and DNA Marker were purchased from TaKaRa (Dalian). The other reagents used were X-a-gal (Clontech, Japan); DNA ligase, pGEM-T, IPTG and X- $\beta$-gal (Promega, USA); EcoR I (Japan TaKaRa), and PCR reaction system.

\section{Phenotypic screening and phenotype confirmation}

Specimen collection, isolation and culture were carried out in strict compliance with National Clinical Laboratory Procedures (3rd edition). The 
resistance of CRKP was analyzed using WHONET 5.6 software. Clinical screening of the 6 CRKP phenotypes was performed according to the procedure described in Clinical and Laboratory Standards Institute (CLSI, 2009), and the NDM-I Pan-resistant Enterobacteriaceae Bacterial Infection Diagnosis and Treatment Guidelines' from China's Ministry of Health and Chinese Medicine Administration [17]. The modified Hodge test confirmed carbapenemases, while the metalloenzyme phenotype was confirmed with EDTA inhibition test.

\section{Extraction of bacterial DNA plasmid}

Colonies cultured overnight on plates were inoculated into $5 \mathrm{ml}$ of LB broth and cultured at $37^{\circ} \mathrm{C}$ for $12-16 \mathrm{~h}$ with shaking at $12000 \mathrm{rpm}$. The cells were pelleted by centrifugation for 2 min, and then the supernatant was completely discarded. All procedures were strictly according to the instructions for plasmid extraction.

\section{PCR amplification and gene sequence analysis}

The primers used for the amplification of the resistant carbapenemase-resistant and ESBLsresistant genes, and the size of the expected products were selected based on data in GenBank (http://www.ncbi.nlm.nih.gov). Various types of bla gene sequence design primers are shown in Table 1 . These primers were synthesized by Invitrogen, USA. The PCR reaction system (total volume $=25 \mu \mathrm{L}$ ) contained $2 \mu \mathrm{L}$ of DNA template, $12.5 \mu \mathrm{L}$ of Premix Taq DNA Polymerase, and a mixture of DNase, buffer, dNTP at 2-fold concentrations for all PCRs (Dalian Bao Bioengineering Co., Ltd.), and $1 \mu \mathrm{L}$ of the corresponding primer. The PCR reaction conditions were: $95{ }^{\circ} \mathrm{C}$ for $5 \mathrm{~min}, 35$ cycles; $94{ }^{\circ} \mathrm{C}$ for $1 \mathrm{~min}, 56{ }^{\circ} \mathrm{C}$ for $30 \mathrm{sec}, 72{ }^{\circ} \mathrm{C}$ for $1 \mathrm{~min}$, and finally $72{ }^{\circ} \mathrm{C}$ for $10 \mathrm{~min}$. The PCR amplification products were electrophoresed on a $1 \%$ agarose gel and stained with Gold View dye. The results were observed with a gel imaging system and photographed. The imaging strip was cut out of the DNA strip under long-wave UV lamp for DNA recovery.

\section{Connection and transformation}

The DNA recovery products were connected with $T$ vector using T4 ligase-dubbed system. After a water bath overnight at $16{ }^{\circ} \mathrm{C}$, the ligation products were transformed with $E$. coli competent cells, with IPTG as an inducer, and Xgal as a staining reagent. The plates were incubated overnight at $37{ }^{\circ} \mathrm{C}$. Blue and white screening were conducted. The white colonies were picked and shaped, and then the bacteria plasmid was obtained. All PCR products were purified and sequenced using Beijing Jinweizhi Technology Co. Ltd. Blast sequence alignment software confirmed the sequencing results.

\section{Statistical analysis}

All experiments were repeated at least 5 times. Data are presented as mean \pm standard deviation (SD). GraphPad Prism program (GraphPad Software, USA) was used for statistical analyses.

Table 1: Primer sequences of drug resistance genes, and the sizes of the amplified fragments

\begin{tabular}{|c|c|c|}
\hline Drug resistance gene & Primer $\left(5^{\prime} \rightarrow 3^{\prime}\right)$ & Size of amplified fragment (bp) \\
\hline blakPC-2 & $\begin{array}{l}\text { GCTACACCTAGCTCCACCTTC } \\
\text { ACAGTGGTTGGTAATCCATGC }\end{array}$ & 989 \\
\hline blasHv & $\begin{array}{l}\text { GGGTTATTCTTATTTGTCGC } \\
\text { TTAGCGTTGCCAGTGCTC }\end{array}$ & 927 \\
\hline blatem & $\begin{array}{l}\text { ATGAGTATTCAACATTTCCGTG } \\
\text { TTACCAATGCTTAATCAGTGAG }\end{array}$ & 861 \\
\hline blaveB & $\begin{array}{l}\text { CGACTTCCATTTCCCGATGC } \\
\text { GGACTCTGCAACAAATACGC }\end{array}$ & 642 \\
\hline blapen & $\begin{array}{l}\text { TGACGATCTGGAACCTTT } \\
\text { AACTGCATAACCTACTCC }\end{array}$ & 850 \\
\hline blactx-м-1 & $\begin{array}{l}\text { ATGGTTAAAAAATCACTGCGC } \\
\text { TCCCGACGGCTTTCCGCCTT }\end{array}$ & 944 \\
\hline bla & $\begin{array}{l}\text { ATGATGACTCAGAGCATTCG } \\
\text { TCCCGACGGCTTTCCGCCTT }\end{array}$ & 900 \\
\hline blactх-м-9 & $\begin{array}{l}\text { CGGCCTGTATTTCGCTGTTG } \\
\text { TCCCGACGGCTTTCCGCCTT }\end{array}$ & 877 \\
\hline blaoxA-1 & $\begin{array}{c}\text { CTGTTGTTTGGGTTTCGCAAG } \\
\text { CTTGGCTTTTATGCTTGATG }\end{array}$ & 720 \\
\hline blaoxA-10 & $\begin{array}{l}\text { GTCTTTCAAGTACGGCATTA } \\
\text { GATTTTCTTAGCGGCAACTTA }\end{array}$ & 720 \\
\hline
\end{tabular}


Treatment groups were compared using one-way analysis of variance (ANOVA) followed by Dunnett's test. Values of $p<0.05$ were considered statistically significant.

\section{RESULTS}

\section{Drug susceptibility}

The results of drug susceptibility test revealed that 6 Klebsiella pneumoniae tested in vitro were resistant to cefotaxime, ceftazidime, cefuroxime, ampicillin, amoxicillin/clavulanic acid, ampicillin/sulbactam, gentamicin, cotrimoxazole, cefepime (FEP), piperacillin/tazobactam, levofloxacin (LEV) and aztreonam. Moreover, the inhibition zones of meropenem, imipenem and cefoperazone/sulbactam were small, while the inhibition zones of polymyxin, minocycline, amikacin, fosfomycin were larger. At the same time, the resistant strains were determined with MIC method (Table 2).

\section{Carbapenemase production by strains}

The modified Hodge test showed positive results for all strains, which confirmed carbapenemase production from the strains. In the test, ATCCBAA-1705 was employed as positive control, while ATCCBAA-1706 was used as negative control. The positive result of strain 089 is shown in Figure 1. Similar results were obtained for the remaining five strains of bacteria.

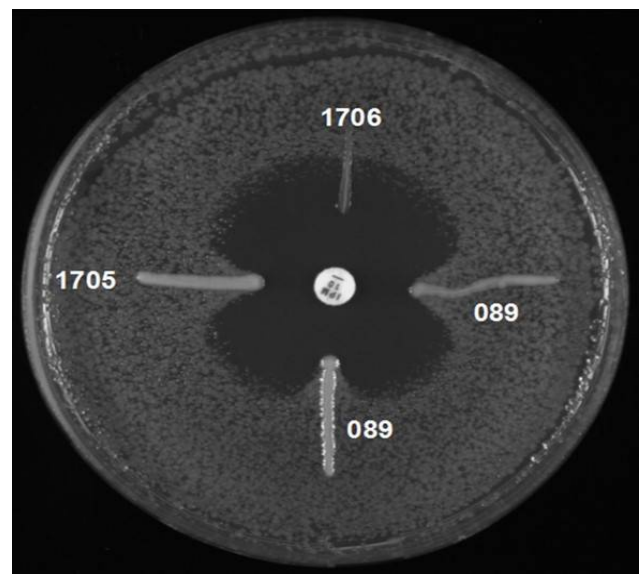

Figure 1: Improved Hodge test results. Strain 089 was positive. ATCCBAA-1705 was employed as the positive control, while ATCCBAA-1706 was used as the negative control

\section{EDTA inhibition}

Double paper synergy tests were performed in the direction of EDTA paper, but imipenem inhibition zone did not expand. Thus, the result of EDTA inhibition test for strain 102 was negative. The other five strains all achieved the same result (Figure 2).

Table 2: Diameters of inhibition zone and breakpoints

\begin{tabular}{|c|c|c|c|c|}
\hline Antibacterial & $\begin{array}{c}\text { Diameter of } \\
\text { inhibition zone } \\
(\mathrm{mm})\end{array}$ & $\begin{array}{l}\text { Breakpoints (K- } \\
\text { B) }(\mathrm{mm})\end{array}$ & $\begin{array}{c}\text { MIC } \\
(\mathrm{mm})\end{array}$ & $\begin{array}{c}\text { Breakpoints } \\
\text { (MIC) (mm) }\end{array}$ \\
\hline Cefotaxime & 6 & $22-26$ & - & - \\
\hline Ceftazidime & 6 & $17-21$ & $\geq 64$ & $4-16$ \\
\hline Cefuroxime & 6 & $14-23$ & $\geq 64$ & $8-32$ \\
\hline Ampicillin & 6 & $13-17$ & $\geq 32$ & $8-32$ \\
\hline $\begin{array}{l}\text { Amoxicillin / } \\
\text { Clavulanic acid }\end{array}$ & 6 & $13-18$ & - & - \\
\hline $\begin{array}{l}\text { Ampicillin / } \\
\text { Sulbactam }\end{array}$ & 6 & $11-15$ & $\geq 32$ & $8 / 4-32 / 16$ \\
\hline Gentamicin & 6 & $12-15$ & $\geq 16$ & $4-16$ \\
\hline Cotrimoxazole & 6 & $10-16$ & $\geq 320$ & $2 / 38-4 / 76$ \\
\hline $\begin{array}{l}\text { Piperacillin / } \\
\text { Tazobactam, }\end{array}$ & 6 & $17-21$ & $\geq 128$ & $16 / 4-128 / 4$ \\
\hline Aztreonam & 6 & $17-21$ & $\geq 64$ & $4-16$ \\
\hline Cefepime (FEP) & 6 & $14-18$ & $\geq 64$ & $8-32$ \\
\hline $\begin{array}{l}\text { Levofloxacin } \\
\text { (LEV) }\end{array}$ & 6 & $13-17$ & $\geq 8$ & $2-8$ \\
\hline Meropenem & 8 & $13-16$ & $\geq 16$ & 4-16 \\
\hline Imipenem & 9 & $13-16$ & $\geq 16$ & $4-16$ \\
\hline $\begin{array}{l}\text { Cefoperazone / } \\
\text { Sulbactam }\end{array}$ & 16 & $15-21$ & - & 一 \\
\hline Polymyxin & 18 & - & - & - \\
\hline Minocycline & 20 & $12-16$ & - & - \\
\hline Amikacin & 24 & $14-17$ & $\leq 2$ & 1664 \\
\hline
\end{tabular}




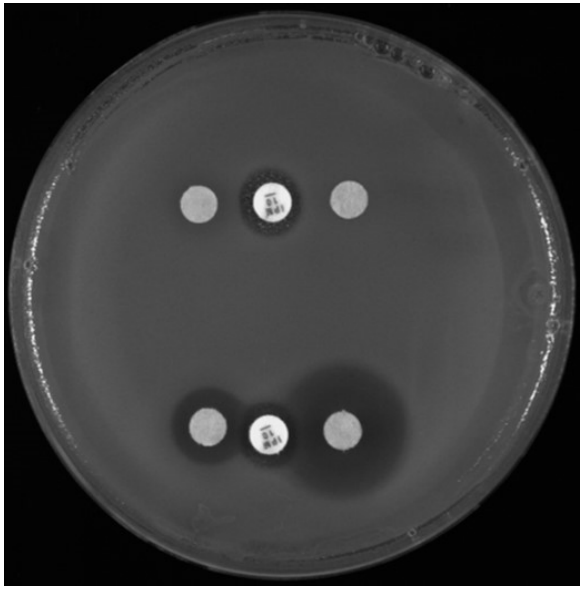

Figure 2: EDTA inhibition results. Double paper synergy tests were performed in the direction of EDTA paper. EDTA inhibition test showed negative result

\section{MIC test results}

The results of MIC on strain 102 are shown in Figure 3. The other five strains all achieved the same result.

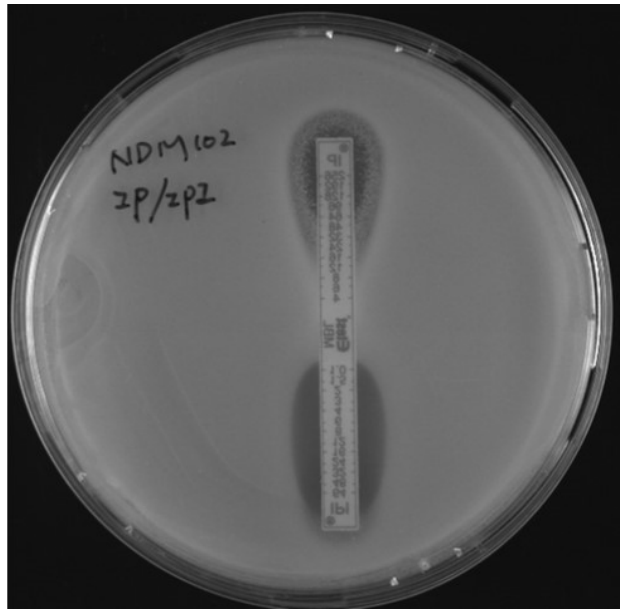

Figure 3: MIC test results for strain 102. The other five strains yielded similar results

\section{FGE maps}

The result of pulsed field gel electrophoresis (PFGE) is shown in Figure 4. The PFGE maps showed that the chromosome bands of the six Klebsiella pneumoniae strains were basically same as those of other strains, and may have originated from the same clone.

\section{Confirmation of drug resistance gene}

The results showed that the six Klebsiella pneumoniae strains all carried drug resistance genes i.e. carbapenemase genes, of which six strains all carried KPC-2 gene, five strains carried SHV gene, and three strains carried TEM gene. Moreover, two strains also carried three kinds of resistance genes.

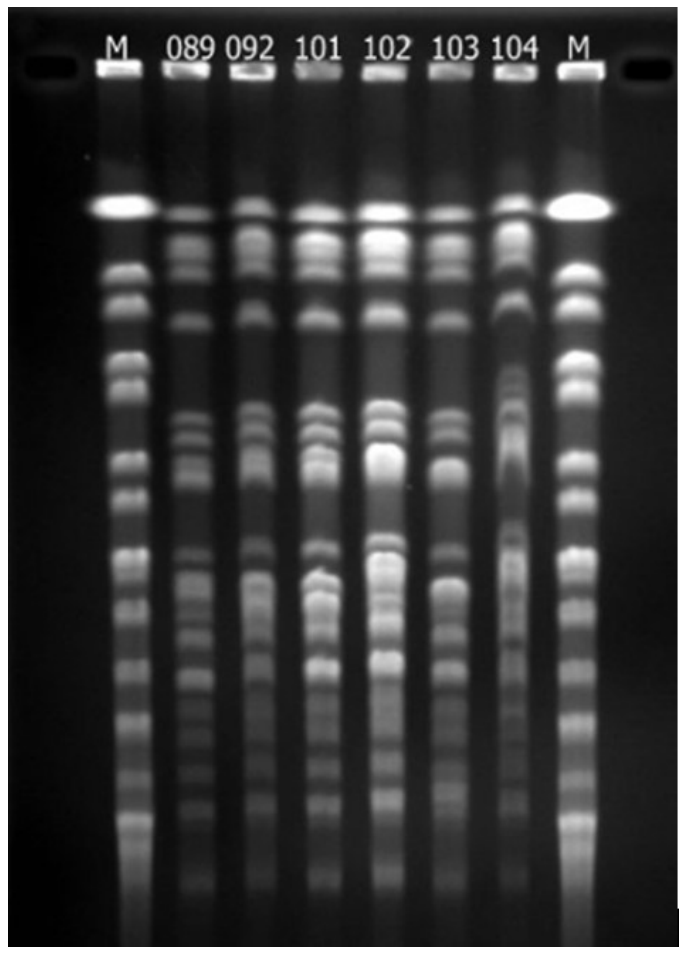

Figure 4: PFGE maps. The chromosome bands of the 6 strains of Klebsiella pneumoniae were basically same as those of other strains. (M: DNA marker; 089, 091, 101, 102, 103 and 104 are the six Klebsiella pneumoniae strains)

\section{DISCUSSION}

Carbapenem antibiotics play an important role in the treatment of clinically serious infections, especially Enterobacteriaceae [18]. However, with the increasing use of clinical carbapenem antibiotics, resistant strains have emerged, mainly against Pseudomonas aeruginosa and Acinetobacter. In recent years, reports of imipenem-resistant Enterobacteriaceae (imipenem-resistant Enterobacter, IRE) have been on the increase [19]. The mechanisms of bacterial antibiotic resistance to carbapenem involve the following (1) high-yielding AmpC enzyme with loss of porin or decreased expression levels, resulting in decreased permeability of antibiotics through the cell membrane; (2) efflux pumpmediated decrease in intracellular antibiotic concentration; (3) alteration of target of carbapenem antibiotics, and (4) production of carbapenemase [20]. In addition, the L1 enzyme of Stenotrophomonas maltophilia has three types of carbapenem antibiotic $\beta$-lactamase (Ambler classification of $A, B, D)$ [21].

Klebsiella pneumoniae carbapenemases (KPC) is a newly discovered carbapenemase belonging 
to the Ambler class $A$, which can hydrolyze almost all $\beta$-lactam antibiotics [1,7]. A total of nine subtypes (KPC 1 - 9) have been identified. However, KPC-1 sequencing was confirmed to be incorrect (http://www.1ahey.org/Studies/) on the grounds that it is actually the same genotype as KPC-2 [7].

Klebsiella pneumoniae carbapenemaseproducing strain was first discovered in the United States, after which KPC enzyme producing strains were found in France, Colombia, Israel, China, Norway, Brazil, Britain, Greece and other regions. These strains were Enterobacteriaceae bacteria, including pneumonia grams Salmonella, Salmonella, Escherichia coli, Enterobacter cloacae, Citrobacter freundii, Serratia marcescens and Proteus mirabilis, and also Pseudomonas aeruginosa and Pseudomonas putida [8]. The KPC-producing strains are resistant to carbapenem-based antibiotics and also resistant to many other antibacterial agents based on transmission of plasmids. The carbapenemresistant Enterobacteriaceae bacteria have become a major clinical challenge [10].

Klebsiella pneumoniae which produces KPC enzymes in hospitals, is found mainly in contaminated medical devices, hands of medical staff, or in the patient's gastrointestinal tract [10]. Klebsiella pneumoniae strains that produce KPC enzymes have been isolated in venous cannulas, bed railings, and sphygmomanometers in patients' rooms [22]. The spread of KPCproducing strains has been reported in the same hospital, between different hospitals and in different regions, and even in different countries. These findings indicate that environmental factors may be involved in infection or bacterial colonization.

In the present study, PFGE results showed that the six isolated strains of Klebsiella pneumoniae belonged to the same clone. The six patients were hospitalized from January 2017 to September 2017, and the cultures of patients who had lived in the same ward yielded the same clone. This indicates that carbapenemaseproducing Klebsiella pneumoniae had a brief clonal spread in the ward during this period. The clonal spread may be due to a variety of medical interventions. Surveillance of nosocomial infections, detection of drug-resistant strains and the timely introduction of precautionary measures are prerequisites for preventing a wider spread.

Detection of KPC enzyme is not only an important part of the control of its spread, but also a basis for clinical drug selection. However, the identification of KPC enzymes is a difficult process because many strains producing KPC enzymes are sensitive to meropenem and imipenem. Moreover, the characteristics of KPC enzymes and ESBLs are similar, and easily misjudged as ESBLs. In addition, the phenotypic identification of local resistant strains is constrained by presence of other carbapenemases (e.g. metal $\beta$-lactamase), culture media, strains and drugs. The susceptibility results showed that the six strains of Klebsiella pneumoniae were resistant to aztreonam, piperacillin/tazobactam, cefotaxime, cefoperazone/sulbactam, and imipene. The sensitivity to meropenem and ertapenein was decreased. The results of PCR showed that the six strains of Klebsiella pneumoniae contained genes of SHV $\beta$-lactamase and TEM gene in addition to KPC-2 gene.

Patient-susceptibility factors to isolates of KPC strains include age, intensive care unit hospitalization, and ventilator use. The six patients used in this study were all aged above 65 years and lived in the same ward, similar to those reported in the literature. In addition, all the six patients had underlying disease. Regarding the use of antibacterial agents in relation to the production of KPC enzymes, it has been reported that only $20 \%$ of 60 patients infected with KPC pathogens used carbapenem antibiotics before the pathogens were isolated, and $60 \%$ of the patients used beta-lactam antibiotics or antibiotics with beta-lactamase inhibitors, while $60 \%$ used quinolone antibiotics [22].

These data suggest that prior treatment with carbapenem antibiotics does not appear to be necessary for the infection or colonization by KPC pathogens. Most of the patients in this study had a history of using antibiotics and antifungal drugs. As confirmed by PFGEE, the six strains of Klebsiella pneumoniae were the same clone. Thus, infection-related pathogens such as hospital-acquired infections may be more important than prior use of antibacterial agents.

The results of drug susceptibility test indicated that polymyxin, timentin, and SMZ-sensitive, combined with polymyxin $B$ and tylinin in the treatment of KPC bacterial infections have been the conventional treatment in some institutions. This treatment is difficult to implement due to difficulty in accessing medicines. Moreover, the treatment is not too effective, resulting in death of patients. Thus, sensitive antibiotics should be sought to strengthen the treatment of underlying diseases and to strengthen the supportive care so as to improve treatment outcomes. Timely release of indwelling needles, intubation and 
other infection-related factors such as comprehensive treatment measures seem to be particularly important. More critical is the rational use of antibiotics to strengthen the monitoring of drug-resistant strains.

\section{CONCLUSION}

The results suggest that the pathogens that contain bla KPC-2 $_{2}$ gene may be involved in the mechanism of Klebsiella pneumoniae resistance to carbapenemFurther studies may help to solve the challenge of resistance to extended-spectrum cephalosporins in Enterobacteriaceae strains in globule. In addition, further studies should lead to the development of important guidance for clinical medication.

\section{DECLARATIONS}

\section{Acknowledgement}

This work was supported by the National Natural Science Foundation of China (nos. 30600524 and 81341067), Guangdong Provincial Science and Technology Program (no. 2017A040405051), Education Project of Industry-University Cooperation (no. 201801186008), and Higher Education Teaching Reform Project of Guangdong in 2017.

\section{Conflict of interest}

No conflict of interest is associated with this work.

\section{Contribution of authors}

We declare that this work was done by the author(s) named in this article and all liabilities pertaining to claims relating to the content of this article will be borne by the authors. All authors read and approved the manuscript for publication. HanHui Lin conceived and designed the study, Danxia Chen, Yan Zhu, Liangshan $\mathrm{Hu}$, Xiaoyun Wu, Mingyou Li, HanHui Lin collected and analysed the data, while Danxia Chen wrote the manuscript.

\section{Open Access}

This is an Open Access article that uses a funding model which does not charge readers or their institutions for access and distributed under the terms of the Creative Commons Attribution License (http://creativecommons.org/licenses/by/ 4.0) and the Budapest Open Access Initiative (http://www.budapestopenaccessinitiative.org/rea d), which permit unrestricted use, distribution, and reproduction in any medium, provided the original work is properly credited.

\section{REFERENCES}

1. Eltai NO, Al Thain AA, Khalid AA, Deshmukh AS, Wehedy E, Al-Hadidi SH, Yassine HM. Molecular characterization of extended spectrum $\beta$-lactamases enterobacteriaceae causing lower urinary tract infection among pediatric population. Antimicrob Resist Infect Control 2018; 7: 90.

2. VanScoy $B D$, Tenero $D$, Turner $S$, Livermore DM, McCauley J, Conde $H$, Bhavnani SM, Rubino CM, Ambrose PG. Pharmacokinetics-Pharmacodynamics of Tazobactam in Combination with Cefepime in an In Vitro Infection Model. Antimicrob Agents Chemother 2017; 61(12): 1476-1478.

3. Khorvash $F$, Yazdani $M$, Shabani $S$, Soudi $A$. Pseudomonas aeruginosa-producing Metallo- $\beta$ lactamases (VIM, IMP, SME, and AIM) in the Clinical Isolates of Intensive Care Units, a University Hospital in Isfahan, Iran. Adv Biomed Res 2017; 6: 147.

4. Zhang $H$, Yang $Q$, Liao $K, N i Y, Y u Y, H u$, Sun Z, Huang $W$, Wang $Y, W u A$, et al. Update of incidence and antimicrobial susceptibility trends of Escherichia coli and Klebsiella pneumoniae isolates from Chinese intraabdominal infection patients. BMC Infect Dis 2017; 17: 776.

5. Rimoldi SG, Gentile B, Pagani C, Di Gregorio A, Anselmo $A$, Palozzi AM, Fortunato $A$, Pittiglio $V$, Ridolfo $A L$, Gismondo $M R$, et al. Whole genome sequencing for the molecular characterization of carbapenem-resistant Klebsiella pneumoniae strains isolated at the Italian ASST Fatebenefratelli Sacco Hospital, 2012-2014. BMC Infect Dis 2017; 17: 666.

6. Onuoha SC. The Prevalence of Antibiotic Resistant Diarrhogenic Bacterial Species in Surface Waters, South Eastern Nigeria. Ethiop J Health Sci 2017; 27: 319-330.

7. Guo L, An J, Ma Y, Ye LY, Luo YP, Tao CM, Yang JY. Nosocomial Outbreak of OXA-48-Producing Klebsiella pneumoniae in a Chinese Hospital: Clonal Transmission of ST147 and ST383. PLOS ONE 2016; 11(8): 0160754.

8. Dias VC, da Silva VL, Barros R, Bastos AN, de Andrade Bastos $L Q$, de Andrade Bastos VQ, Diniz CG. Phenotypic and genotypic evaluation of beta-latamases (ESBL and KPC) among enterobacteria isolated from community-acquired non-microbial urinary tract infections. J Chemother 2014; 26: 328-332.

9. Qureshi ZA, Hittle LE, O'Hara JA, Rivera JI, Syed A, Shields RK, Pasculle AW, Ernst RK, Doi Y. ColistinResistant Acinetobacter baumannii: Beyond Carbapenem Resistance. Clin Infect Dis 2015; 60(9): 1295-1303.

10. Falcone $M$, Russo A, lacovelli A, Restuccia G, Ceccarelli G, Giordano $A$, Farcomeni $A$, Morelli $A$, Venditti $M$. Predictors of outcome in ICU patients with septic shock 
caused by Klebsiella pneumoniae carbapenemaseproducing K. pneumoniae. Clin Microbiol Infect 2016; 22(5): 444-450.

11. Dong $F$, Lu J, Wang $Y$, Shi J, Zhen JH, Chu P, Zhen $Y$, Han SJ, Guo YL, Song WQ. A Five-year Surveillance of Carbapenemase-producing Klebsiella pneumoniae in a Pediatric Hospital in China Reveals Increased Predominance of NDM-1. Biomed Environ Sci 2017; 30: 562-569.

12. Gartzonika K, Rossen JWA, Sakkas H, Rosema S, Priavali E, Friedrich AW, Levidiotou S, Bathoorn E. Identification of a KPC-9-producing Klebsiella pneumoniae ST258 cluster among KPC-2-producing isolates of an ongoing outbreak in Northwestern Greece: a retrospective study. Clin Microbiol Infect 2018; 24(5): 558-560.

13. Liu J, Yu J, Chen F, Yu J, Simner $P$, Tamma $P$, Liu $Y$, Shen $L$. Emergence and establishment of KPC-2producing ST11 Klebsiella pneumoniae in a general hospital in Shanghai, China. Eur J Clin Microbiol Infect Dis 2018; 37(2): 293-299.

14. Santucci M, Spyrakis F, Cross S, Quotadamo A, Farina $D$, Tondi $D$, De Luca F, Docquier JD, Prieto Al, Ibacache $C$, et al. Computational and biological profile of boronic acids for the detection of bacterial serine- and metallo- $\beta$ lactamases. Sci Rep 2017; 7: 17716.

15. Okoche D, Asiimwe BB, Katabazi FA, Kato L, Najjuka CF. Prevalence and Characterization of CarbapenemResistant Enterobacteriaceae Isolated from Mulago National Referral Hospital, Uganda. PLOS ONE 2015; 10(8): 0135745.

16. World Health Organization. Declaration of Helsinki. Br Med J 1996; 313(7070): 1448-1449.
17. Kassim A, Omuse G, Premji Z, Revathi G. Comparison of Clinical Laboratory Standards Institute and European Committee on Antimicrobial Susceptibility Testing guidelines for the interpretation of antibiotic susceptibility at a University teaching hospital in Nairobi, Kenya: a cross-sectional study. Ann Clin Microbiol Antimicrob 2016; 15(1): 21.

18. Marcoccia F, Leiros HS, Aschi M, Amicosante G, Perilli $M$. Exploring the role of $L 209$ residue in the active site of NDM-1 a metallo- $\beta$-lactamase. PLoS One 2018; 13: 0189686.

19. El-Domany RA, Emara M, El-Magd MA, Moustafa WH, Abdeltwab NM. Emergence of Imipenem-Resistant Pseudomonas aeruginosa Clinical Isolates from Egypt Coharboring VIM and IMP Carbapenemases. Microb Drug Resist 2017; 23(6): 682-686.

20. Corso A, Guerriero L, Pasterán F, Ceriana P, Callejo R, Prieto $M$, Tuduri E, Lopardo $H$, Vay $C$, Smayevsky J, et al. Capability of national reference laboratories in Latin America to detect emerging resistance mechanisms. Rev Panam Salud Publica 2011; 30: 619-626.

21. Bedenić B, Sardelić S, Luxner J, Bošnjak Z, Varda-Brkić $D$, Lukić-Grlić A, Mareković I, Frančula-Zaninović $S$, Krilanović $M$, Šijak $D$, et al. Molecular characterization of class $b$ carbapenemases in advanced stage of dissemination and emergence of class $d$ carbapenemases in Enterobacteriaceae from Croatia. Infect Genet Evol 2016; 43: 74-82.

22. Chi H, Holo H. Synergistic Antimicrobial Activity between the Broad Spectrum Bacteriocin Garvicin KS and Nisin, Farnesol and Polymyxin B Against Gram-Positive and Gram-Negative Bacteria. Curr Microbiol 2018; 75(3): 272-277. 